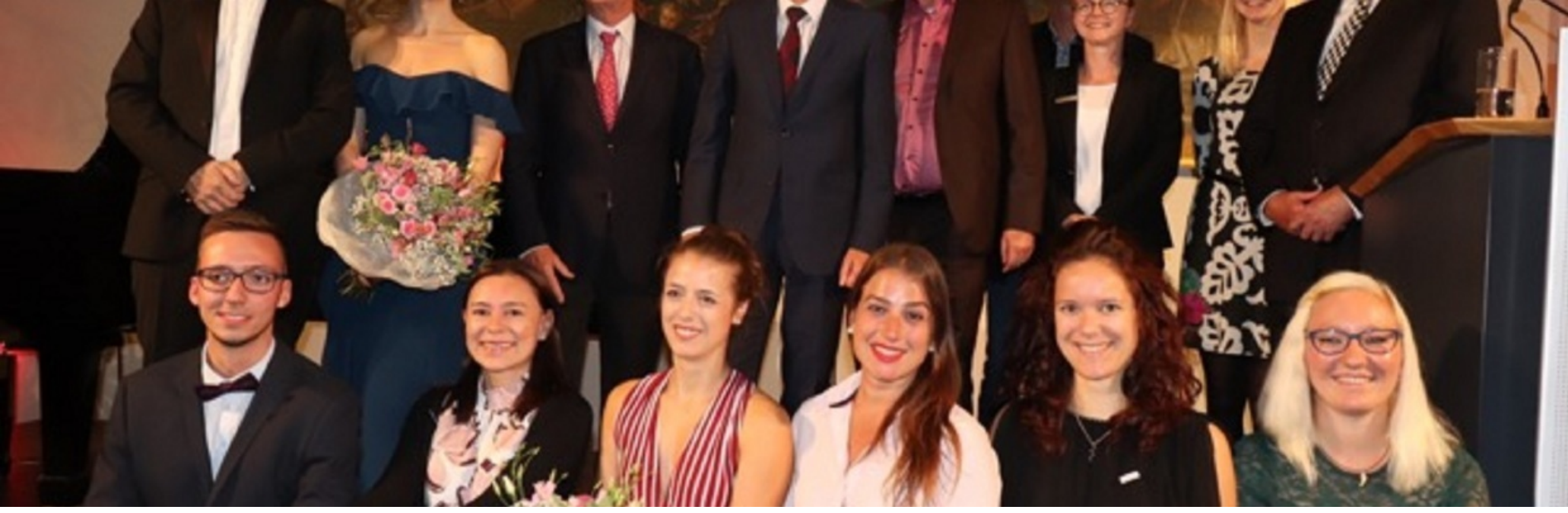

\title{
Art - The mother of all discoveries
}

Authors: Zazie-Charlotte Pfeiffer, Stephan Seiler

Submitted: 22. November 2018

Published:

Volume:

Issue:

Affiliation:

Languages:

Keywords:

Categories:

DOI:

\author{
27. November 2018
}

5

9

JOSHA

English

Music, Conference, Culture, Poems, Demetrios Prize, Freiburg Demetrios Project, News and Views

10.17160/josha.5.9.506

\section{Abstract:}

Science meets art! The International Academy of Sciences, Humanities, and Arts organizes a successful concert for the second time. With the motto "Art opens the mind and heart," the deputy chairman of IASHA e. V. Prof. dr. Dr. h.c. mult. Roland Mertelsmann opens the successful symbiosis of music, poetry and scientific talent development. The event was hosted by IASHA e.V. and Marcel Thimm, CEO of Sparkasse Freiburg. IASHA e.V. is a non-profit organization with the aim of creating and supporting the international and interdisciplinary exchange between researchers, artists, philosophers and interested parties. The focus is on promoting young scientists and artists through scholarships, prizes and the opportunity to publish in the Journal of Sciences, Humanities, and Arts.

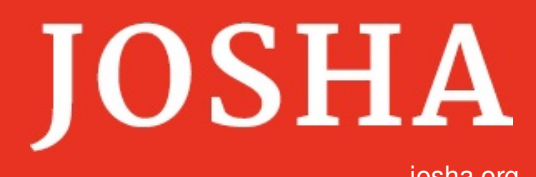

josha.org
Journal of Science,

Humanities and Arts

JOSHA is a service that helps scholars, researchers, and students discover, use, and build upon a wide range of content 


\section{Art- The mother of all discoveries}

\section{A concert with the soprano Kim-Lillian Strebel and the poet Zazie- Charlotte Pfeiffer}

Science meets art! The International Academy of Sciences, Humanities, and Arts organizes a successful concert for the second time. With the motto "Art opens the mind and heart," the deputy chairman of IASHA e. V. Prof. dr. Dr. h.c. mult. Roland Mertelsmann opens the successful symbiosis of music, poetry and scientific talent development. The event was hosted by IASHA e.V. and Marcel Thimm, CEO of Sparkasse Freiburg.

IASHA e.V. is a non-profit organization with the aim of creating and supporting the international and interdisciplinary exchange between researchers, artists, philosophers and interested parties. The focus is on promoting young scientists and artists through scholarships, prizes and the opportunity to publish in the Journal of Sciences, Humanities, and Arts.

\section{Songs and Arias by Kim-Lillian Strebel}

Musically, Kim-Lillian Strebel designed the evening. The soprano is no stranger in Freiburg, as she was a member of the ensemble of the local city theater from 2014-2017. Here she sang, for example, the roles of Lucette in Jules Massenet's Cendrillon, Fiordiligi in Wolfgang Amadeus Mozart's Così fan tutte, and finally Isaure in Giuseppe Verdi's Jerusalem. In addition, she was a scholarship holder of the IASHA e.V. in 2016/2017 and sang at a concert

at the Sparkasse Freiburg in the course of last year's event. Again, Kim-Lillian proved that she not only masters the operatic subject to perfection but also has a full presence in voice and performance in her song-play. Thus began the lecture with a selection of three pieces of the song-soiree of the opera composer Gioachino Rossini. He wrote the songs after completing his career as an opera composer and devoted himself to instrumental music, sacred work and passion as a chef in Paris.

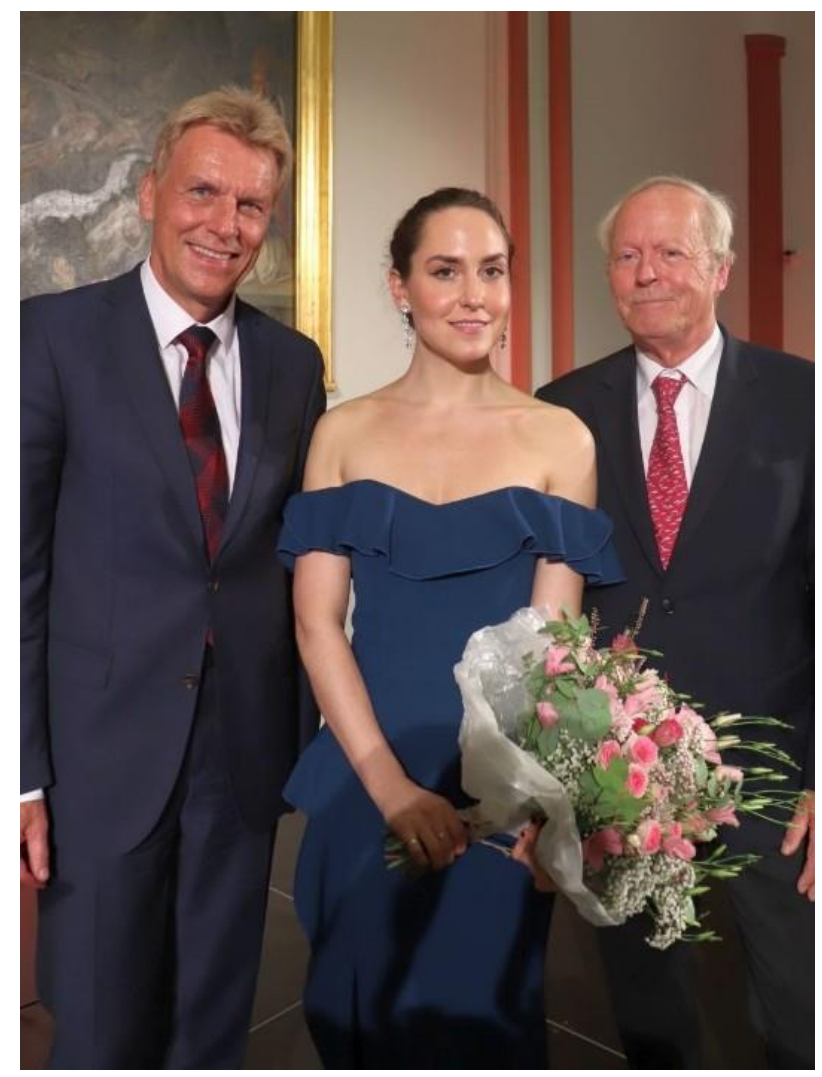

Marcel Thimm, CEO Sparkasse Freiburg, Kim-Lillian Strebel und Prof. Dr. Dr. h.c. mult. Roland Mertelsmann, Vice-President IASHA e.V. 


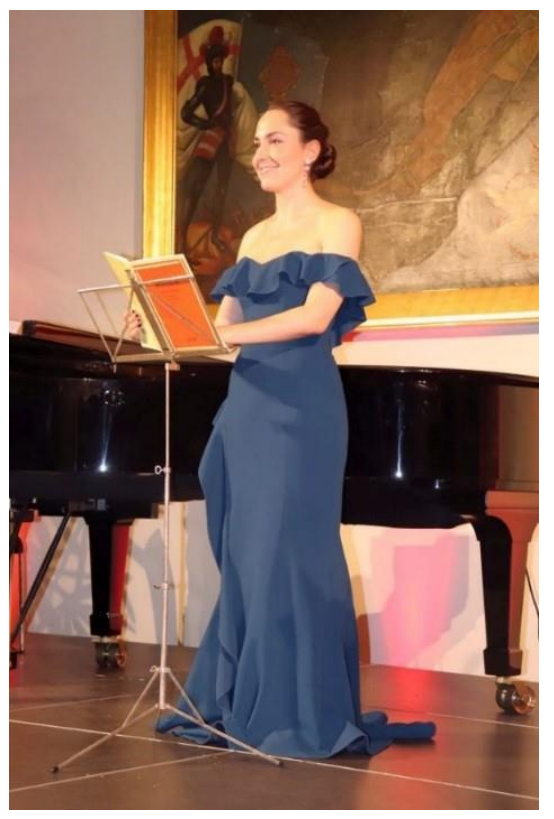

Kim-Lillian Strebel in the Meckelhalle Sparkasse Freiburg
This was followed by two operatic arias of the classical repertoire: "Deh vieni, non tardar, o Gioia Bella" from Mozart's Nozze di Figaro and "Come scolgio" from Così fan tutte. After the poetic contribution by Zazie-Charlotte Pfeiffer and the presentation of the Demetrios Prize to young scientists, the second part of the concert was followed by arias of the Italian- French romantic repertoire. It all started with the aria of Adelia from Gaetano Donizetti's opera of the same name, whose German premiere Kim-Lillian Strebel sang in Hildesheim. This was followed by Marguerite's "O dieu que de Bijoux" from Charles Gounod's Faust and an aria by Jules Massenet's Cendrillon, which she sang in Freiburg and from which a DVD production is available on the market. The evening ended with an aria from Rusalka by Antonin Dvořák, which she will sing in America in two years. Kim-Lillian is now internationally known and gets engagements from Germany, Italy, Austria, and the USA. She has a wide repertoire of song, oratorio, and opera, where she excels as a lyric soprano, especially in the classical-romantic subject. Her voice commands all the layers required for the subject with security, color, and dynamics. Her portrayal in facial expressions and gestures ranges from lyrical to dramatic and does not seem to be set up at any time. She was congenially accompanied by the British pianist David Cowen.

\section{Prose by Zazie-Charlotte Pfeiffer}

Art lives on its diversity, and so Zazie- Charlotte Pfeiffer designed the second part of the evening with a lecture on the short story she wrote: "At Night". The starting point of the story is a summer night in which the protagonist does not sleep and thinks about her childhood, her relationship and life as a young person in general. That same night, after some emotional turmoil, she finds herself experiencing a moment of beauty and luck. The seriousness of the text is permeated with subtle humor and hinted erotica.

Zazie-Charlotte Pfeiffer manages to

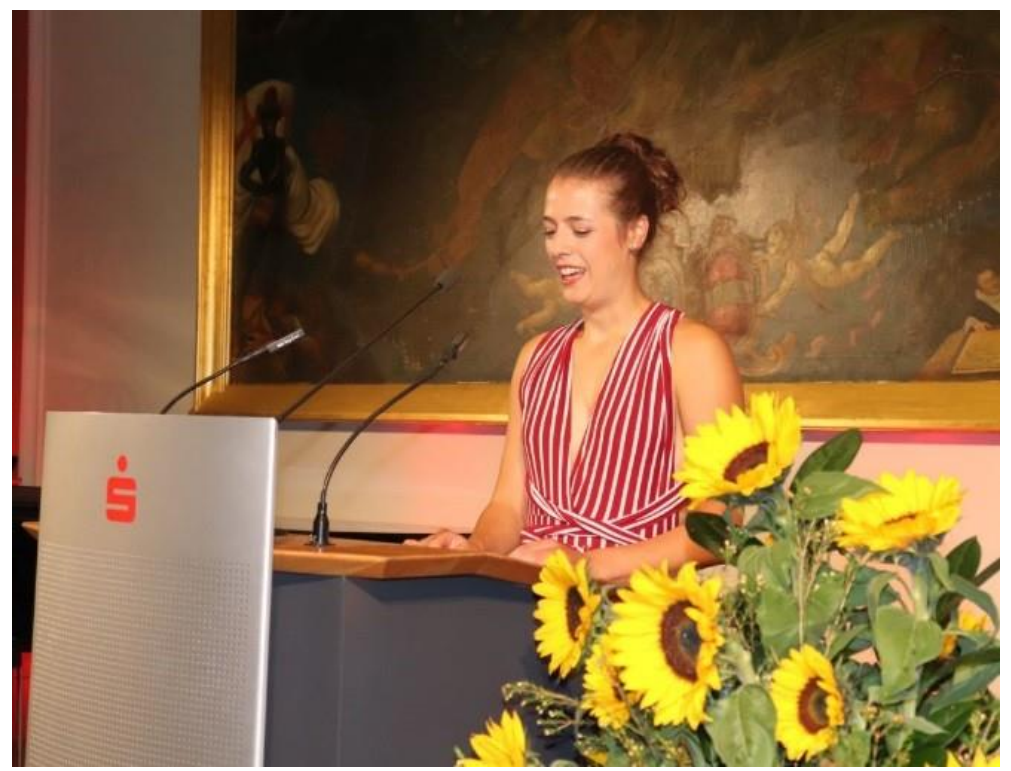
create images that are known to everyone and that everyone can imagine in their mind's eye to promote. 


\section{The presentation of the Demetrios prizes}

Following the strong performances of Kim-Lillian Strebel and Zazie-Charlotte Pfeiffer, the Demetrios Prize of he International Academy of Sciences, Humanities and Arts e.V. was the final highlight of the evening for young junior researchers. The name of the prize is based on the Greek philosopher Demetrios of Phaleron. He was one of the leaders of the famous library of Alexandria, where the knowledge of the ancient world was gathered. IASHA also sees itself as an association in which knowledge is promoted and so the idea was born to promote for the first time in 2018 four junior researchers with a price of $€ 500$. The winners come from different scientific disciplines: Leah Biebert received an award for her bachelor thesis on "Carl Orff's Trionfi Trilogy" and Orff's role in the Third Reich, Elena Riccarda Fellner for her bachelor thesis on the "Iranian activist, politician and intellectual Zahrā Rahnavard and the Iranian women's rights movement in the 20th century", Nora Marie Leps for her scientific work on the "religiosity of Christian and Muslim youth in Germany" and Simon Osterkamp for a "comparison of preclinical characterization methods of a radiopharmaceutical ". Board member Prof. Dr. med. Gerhard Steinmann awarded the prizes. All papers have also been published online in the Journal of Sciences, Humanities, and Arts. (www.josha-journal.org)

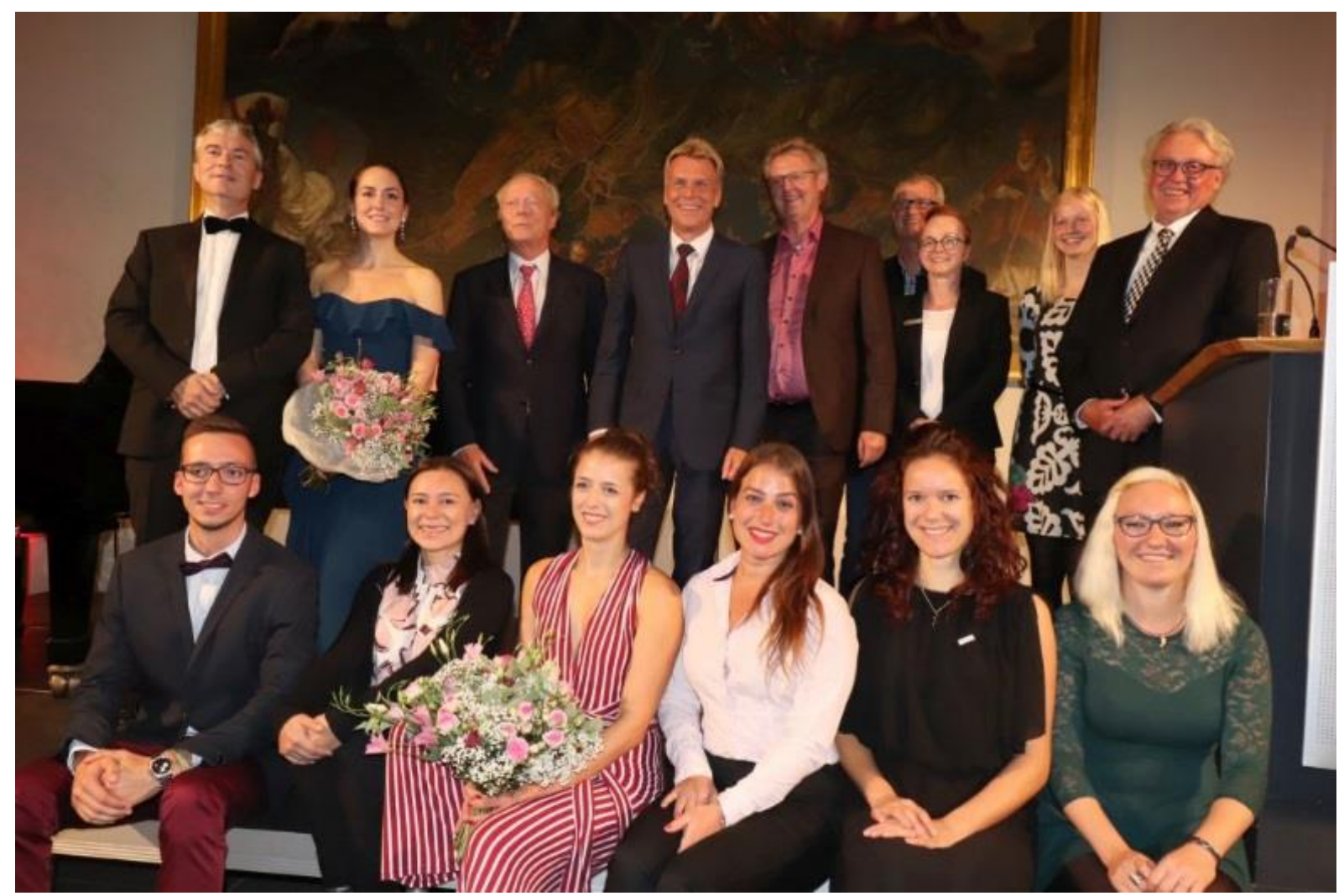

The Demetrios-winners 2018, Marcel Thimm, the mayor of Freiburg for culture, youth, social affairs and integration Ulrich von Kirchbach and members of IASHA e.V. 
